\title{
Strategi Komunikasi Pemasaran Salon Dreadock Studio Indonesia
}

\author{
Claudio Tjahjadi, Gregorius Genep Sukendro \\ claudiotjahjadi@gmail.com, geneps@fikom.untar.ac.id \\ Fakultas Ilmu Komunikasi Universitas Tarumanagara
}

\begin{abstract}
Dreadock Studio Indonesia is a dreadlock salon in the city of Bandung. The establishment of this salon is motivated by the owner Docko who wants to change the society's stigma towards dreadlocks. This studio provides services related to dreadlocks, from dreadlocking hair, repairing dreadlocks, and doing treatment. The purpose of this study aims to analyze marketing strategies to attract consumers through marketing communications carried out by Dreadock Studio. This research is a qualitative study using a case study method. The theories used in this study include marketing communications, event marketing, events sponsorship, and word of mouth. Data collection for this study uses interviews with Docko as the owner of the Dreadock, observation and literature study. The conclusion of the marketing communication strategy research conducted by Dreadock Studio to attract these consumers is by word of mouth and events.
\end{abstract}

Keywords: Marketing Communication, Word of Mouth, Event Marketing, Event Sponsorship.

\begin{abstract}
Abstrak
Dreadock Studio Indonesia adalah sebuah salon rambut gimbal yang berada di Kota Bandung. Berdirinya salon ini dilatar belakangi oleh Docko sang pemilik yang ingin mengubah stigma masyarakat terhadap gaya rambut gimbal. Salon ini menyediakan jasa yang berkaitan dengan rambut gimbal, mulai dari menggimbal, repair rambut gimbal, hingga melakukan perawatannya. Maksud dari penelitian ini bertujuan untuk menganalisis strategi pemasaran untuk menarik konsumen melalui komunikasi pemasaran yang dilakukan oleh Dreadock Studio. Penelitian ini merupakan penelitian kualitatif dengan menggunakan metode studi kasus. Adapun teori yang digunakan di dalam penelitian ini, diantaranya seperti komunikasi pemasaran, event marketing, event sponsorship, dan juga word of mouth. Pengumpulan data untuk penelitian ini menggunakan wawancara dengan Docko sebagai pemilik Dreadock, observasi dan juga studi pustaka. Kesimpulan dari penelitian strategi komunikasi pemasaran yang dilakukan Dreadock Studio untuk menarik konsumen ini adalah dengan word of mouth dan event.
\end{abstract}

Kata kunci: Komunikasi Pemasaran, Word of Mouth, Event Marketing, Event Sponsorship.

\section{Pendahuluan}

Dreadock Studio Indonesia, berlokasi di Jalan Bukit Dago Selatan 1 no.4, Bandung. Dreadock Studio atau yang bisa di sebut dengan DDS, merupakan sebuah salon yang berlokasi di kota Bandung. Seperti pada salon kebanyakan, Dreadock Studio Indonesia juga menyediakan jasa perawatan rambut dan perawatan lain seperti salon biasa nya. Namun Dreadock Studio ini mempunyai keunikan dibanding salon lain nya, yaitu menyediakan jasa untuk orang yang ingin mempunyai gaya rambut gimbal. Selain jasa untuk membuat rambut gimbal, Dreadock Studio juga menyediakan jasa untuk orang berambut gimbal yang ingin melakukan perawatan. di 
Dreadock Studio juga menjual banyak aksesoris dan barang lain yang berkaitan dengan rambut gimbal.

Seorang pemuda Bandung bernama Dicky Alfarizy adalah orang yang membangun Dreadock Studio. Membuka usaha salon gimbal ini di Indonesia sangat unik dikarenakan Indonesia yang erat dengan budaya orang timur. Hal tersebut tentu menjadi tantangan tersendiri bagi Dreadock Studio dalam melakukan pemasaran untuk menarik pelanggan atau konsumen. Docko mengaku salah satu alasan nya membuka usaha ini adalah untuk mengubah stigma tentang rambut gimbal selama ini yang kerap dikaitkan dengan ganja, reggae, bau, kucel dan lain-lain nya.

Rumusan masalah dan tujuan dalam penelitian ini adalah untuk mengetahui bagaimana Dreadock Studio melakukan komunikasi pemasarannya untuk menarik konsumen. Komunikasi merupakan salah satu aspek yang paling utama dan yang paling penting di dalam kehidupan manusia. Komunikasi itu sendiri merupakan proses dimana ide dialihkan dari sumber kepada suatu penerima atau lebih, dengan maksud untuk mengubah tingkah laku mereka. Di era modern yang semakin berkembang ini, komunikasi pun harus ikut terus berkembang. Hal tersebut dilakukan agar komunikasi yang dilakukan tetap efektif dan pesan dapat tersampaikan dengan baik. Sebagai sebuah ilmu, komunikasi mempunyai banyak aspek yang berkaitan dan berpengaruh dalam kehidupan manusia. Salah satunya adalah komunikasi pemasaran yang akan dilakukan dalam penelitian ini.

Dalam penelitian ini, salah satu pemasaran yang dapat terlihat dilakukan oleh Dreadock Studio adalah melalui media sosial. Seperti contohnya adalah Facebook, Twitter, Instagram, dan Youtube yang merupakan media baru. Seiring berkembangnya jaman, media sosial merupakan salah satu media untuk berkomunikasi yang berperan penting dalam masyarakat. Lalu pemasaran lain yang terlihat dilakukan oleh Dreadock Studio adalah melalui event. Dreadock Studio terlihat mengadakan event ataupun menjadi sponsor sebuah event. Hal tersebut pasti nya dilakukan sebagai bentuk salah satu pemasaran yang dilakukan. Banyak maanfaat yang didapatkan dari melakukan kegiatan event ini. Maka event marketing juga merupakan salah satu komunikasi pemasaran yang akan di teliti di penelitian ini. Yang terakhir terlihat dilakukan Dreadock Studio adalah word of mouth. Komunikasi pemasaran tersebut terjadi secara alamiah, jadi bisa di bilang tanpa di sengaja namun komunikasi ini terjadi.

\section{Metode Penelitian}

Dalam penelitian ini, penulis menggunakan pendekatan penelitian kualitatif. Penelitian ini dilakukan oleh penulis untuk mengetahui strategi komunikasi pemasaran salon Dreadock Studio dalam menarik minat konsumen. . Menurut Sugiyono (2010), penelitian kualitatif adalah cara ilmiah untuk mendapatkan data valid dengan tujuan yang dapat ditemukan, dikembangkan dan dibuktikan oleh pengetahuan tertentu sehingga pada gilirannya dapat digunakan untuk memahami, memecahkan, serta mengantisipasi masalah dalam bidang pendidikan.

Metode penelitian yang digunakan oleh peneliti dalam penelitian skripsi ini adalah dengan menggunakan metode studi kasus. Menurut Creswell (2009), studi kasus dalam buku berjudul Metode Penelitian Kualitatif Teori dan Praktik dalam (Gunawan, 2014) mengatakan bahwa penelitian studi kasus adalah penelitian yang digunakan terhadap suatu objek, yang disebut sebagai kasus, yang dilakukan secara 
seutuhnya, menyeluruh dan mendalam dengan menggunakan berbagai macam sumber data.

Peneliti menggunakan studi kasus sebagai metode penelitian dikarenakan peneliti ingin mencari dan mengetahui serta mengumpulkan informasi lebih mendalam pada kasus dan juga permasalahan yang ada. Didalam penelitian ini, kasus dan fenomena yang diambil adalah salon Dreadock Sudio yang memiliki ciri khas menyediakan jasa gimbal rambut. Nantinya untuk mengumpulkan informasi tersebut, peneliti akan menggunakan metode wawancara, observasi, dan studi kepustakaan.

Pada penelitian ini, peneliti memakai beberapa teknik pengumpulan data seperti; wawancara, observasi, studi kepustakaan. Subjek dalam penelitian ini adalah Dicky Alfarizy selaku pemilik Dreadock Studio. Sedangkan Objek dalam penelitian ini adalah strategi komunikasi pemasaran yang digunakan oleh Ddreadock Studio. Sehingga peneliti dapat mendalami mengenai aktivitas yang dilakukan oleh Dreadock Studio untuk menarik konsumen.

Analisis data menggunakan teknik analisis data interaktif (interctive model of analysis) yang terdiri dari tiga komponen analisis data, yaitu reduksi data, penyajian data, dan penarikan kesimpulan. Reduksi data, penyajian data, dan penarikan kesimpulan menjadi gambaran keberhasilan secara berurutan sebagai rangkaian kegiatan analisis yang saling menyusul (Milles dan Michael Huberman, 2007: 15).

Sedangkan teknik keabsahan yang digunakan didalam penelitian ini adalah dengan menggunakan Teknik triangulasi. Triangulasi merupakan teknik pemeriksaan data, dimana teknik ini memanfaatkan sesuatu yang lain. Diluar data tersebut, untuk keperluan pengecekan atau sebagai pembanding data itu. Teknik triangulasi yang paling banyak digunakan adalah pemeriksaan melalui sumber lainnya (Moleong, 2009:330).

\section{Hasil Temuan dan Diskusi}

Dreadock Studio Indonesia merupakan salon yang didirikan sejak tahun 2013. Awal mula terbentuk usaha salon ini dimulai sejak tahun 2008, namun baru direalisasikan menjadi sebuah salon sejak tahun 2013. Salon yang berada di Bandung jalan Bukit Dago Selatan 1 nomor 4 ini tidak seperti salon pada umumnya. Dreadock Studio merupakan salon yang selain menyediakan jasa barber untuk pria, namun juga mempunyai keunikan menyediakan jasa gimbal rambut dan juga perawatan lain nya yang berkaitan dengan rambut gimbal. Pendiri dan pemilik salon ini adalah Dicky Alfarizy, seorang pemuda bandung yang tertarik dengan gaya rambut gimbal. Dicky yang biasa akrab dipanggil Docko ini memulai usaha karena melihat ada nya pasar dimana orang meminati jasa gimbal rambut. Namun Selain melihat peluang usaha, salah satu tujuan Docko membuka usaha gimbalnya ini adalah untuk mengubah stigma tentang gimbal selama ini. Docko membangun usaha nya ini untuk menjadi wadah dimana orang-orang yang tertarik dan mempunyai rambut gimbal dapat dengan mudah mencari tempat untuk mendapatkan jasa gimbal rambut dan tempat untuk melakukan perawatan rambut gimbalnya. 


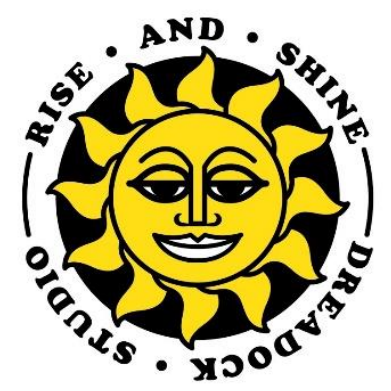

\section{Gambar 1. Logo Dreadock Studio Sumber: Dokumentasi Pribadi}

Hasil temuan dan diskusi dari penelitian ini akan dibagi kedalam konsep pembahasan yang akan dijelaskan sebagai berikut:

a. Bauran Pemasaran Jasa

Zeithhaml dan Bitner (2008) dalam buku Komunikasi Pemasaran Terpadu (Priansa, 2017) menjelaskan tujuh komponen dalam bauran pemasaran jasa, yakni sebagai berikut :

1. Produk (product)

Produk merupakan merupakan kombinasi dari barang dan jasa yang ditawarkan perusahaan kepada pasar sasarannya. Dreadock Studio merupakan salon yang bergerak di bidang jasa, namun dengan seiringnya waktu Dreadock juga mulai mengeluarkan produk dengan brand Dreadock itu sendiri. Seperti pada salon umumnya Dreadock menyediakan jasa yang berhubungan dengan perawatan rambut, tapi kegiatan perawatan rambut ini lebih di peruntukan untuk orang yang ingin menggimbal rambut dan sudah berambut gimbal.

2. Tempat/saluran distribusi (place)

Dreadock studio berlokasi di Kota Bandung, Kota Bandung ini sendiri merupakan kota kelahiran dari Docko sang pemilik. Dreadock merupakan gedung dua lantai dengan sebuah basement yang berlokasi di Jalan Bukit Dago Selatan 1 nomor 4. Dreadock ganyak menggunakan 1 lantai untuk studionya dan basement sebagai toilet nya. Lantai dua Gedung nya digunakan oleh rekannya untuk membuka cafe kopi.

3. Promosi (promotion)

Kegiatan promosi ditujukan untuk memberikan informasi, membujuk, serta memperingatkan konsumen tahap produk dengan tujuan menciptakan penjualan yang diinginkan. Dreadock mempunyai beberapa promosi yang dilakukan untuk melakukan komunikasi kepada konsumennya. Salah satu promosi utama Dreadock adalah dengan menggunakan media sosial. Selain itu event dan sponsorship juga merupakan kegiatan promosi yang dilakukan Dreadock.

4. Harga (price)

Harga merupakan satu-satunya elemen bauran pemasaran yang menghasilkan pendapatan. Dreadock merupakan pemasaran jasa, sehingga pengukurannya harga atau biaya nya tidak bisa ditentukan seperti harga pada sebuah produk. Menurut Docko cara penentuan harga jasa yang Ia berikan adalah melalui pengalamannya. Pengalaman yang selama ini dia kerjakan sebagai profesi gimbal rambut membuatnya dapat memberikan 
patokan dan penilaian secara harga. Lalu dari situ Ia mulai mebuat standarisasi harga berupa price list yang nanti nya berlaku.

5. Orang (people)

Merupakan orang atau pegawai yang memberikan persepsi kepada konsumen lain tentang kualitas jasa yang pernah dibelinya dari perusahaan sehingga hal tersebut berpengaruh terhadap proses pembelian jasa yang bersangkutan. Menurut Docko pegawai nya harus berkomitmen dan tentunya tau hal yang berkaitan dengan gimbal rambut. Docko mempunyai misi untuk menjadikan profesi rambut gimbal ini dapat dipandang orang. Sehingga Ia pun lebih setuju jika kata seniman lebih cocok daripada pegawai. Ia lebih memilih seperti partnership daripada atasan dan bawahan di studionya.

6. Bukti Fisik (physical evidence)

Bukti fisik merupakan suatu hal yang secara nyata turut memiliki kepuasan untuk membeli dan menggunakan produk jasa yang ditawarkan. Bukti fisik dari sebuah usaha jasa tentu nya sangat berpengaruh nanti nya dengan pemasaran yang dilakukan. Bukti fisik yang bisa terlihat dari Dreadock tentunya adalah service-nya. Dari service-nya konsumen nanti dapat menilai dan dapat menimbulkan image terhadap Dreadock. Selain sevice, salah satu bukti fisik yang dapat terlihat di Dreadock adalah dengan konsep salon nya.

7. Proses (process)

Proses adalah cara menyampaikan nilai jasa tersebut kepada konsumen. Konsumen dapat menilai jasa yang diberikan dalam proses ini. Proses jasa yang dilakukan Dreadock sendiri pasti nya sangat berpengaruh. Proses yang lama tentunya akan dialami oleh konsumen karena menggimbal rambut memang membutuhkan waktu yang tidak sebentar. Sehingga menurut Docko yang berpengaruh dalam proses ini adalah bukan merupakan lama waktunya, namun lebih ke bagimana konsumen dapat menghabiskan waktu saat melakukan proses jasanya dengan enjoy.

\section{b. Bauran Promosi Dreadock Studio}

Menurut Kotler dan Armstrong (2012), bauran promosi terdiri atas lima alat-alat promosi, yaitu:

1. Periklanan (advertising)

Iklan adalah semua bentuk presentasi dan promosi nonpersonal yang dibayar atau pun tanpa bayaran oleh perusahaan untuk mempresentasikan gagasan, barang atau jasa. Dalam promosi untuk mengiklankan studionya, Dreadock hanya mengiklankan melalui Instagram. Tentu nya di zaman dimana media terus berkembang, media sosial merupakan salah satu media yang efektif digunakan sebagai tempat beriklan. Selain mudah diakses oleh banyak orang, media sosial dapat dibilang mempunyai biaya yang paling sedikit dibanding media lain dalam mengiklankan. Penggunaan media sosial ini pun merupakan salah satu cara mengiklankan yang terbaik untuk Dreadock karena brand nya yang masih belum kuat dan belum banyak orang kenal. 
2. Promosi penjualan (sales promotion)

Promosi penjualan merupakan insentif-insentif jangka pendek untuk mendorong pembelian atau penjualan suatu produk atau jasa. Dreadock juga melakukan promosi penjulan, namun promosi penjualan ini tidak sering dilakukan. Docko mengatakan ada beberapa jenis promosi yang pernah Ia lakukan, yaitu seperti diskon, free stuff, lima orang pertama yang gimbal di salah satu bulan dapat baju, dan lain-lain. Docko juga mengatakan sering melakukan promosi di bulan-bulan tertentu dimana terdapat hari spesial yang berlangsung di Indonesia.

3. Penjualan perseorangan (personal selling)

Penjualan perseorangan merupakan presentasi personal oleh tenaga penjualan dengan tujuan menghasilkan penjualan dan membangun hubungan dengan konsumen. Menurut Docko personal selling merupakan tahapan yang sedang Dreadock lakukan. Docko menyadari sosok nya penting sebagai pemilik Dreadock, sehingga Ia mengusahakan untuk menaikkan personal branding nya. Sebagai pemilik salah satu strategi yang Docko lakukan adalah dengan ngobrolin dreadlocks ke berbagai banyak pihak. Menurut nya jika dimulai dengan diri nya sendiri, personal selling yang dilakukan akan dapat mengembangkan studio atau brand dari Dreadock itu sendiri.

4. Hubungan masyarakat (public relations)

Hubungan masyarakat adalah untuk membangun hubungan yang baik dengan berbagai publik perusahaan supaya memperoleh publisitas yang menguntungkan, membangun citra perusahaan yang bagus, dan menangani atau meluruskan rumor, cerita, serta event yang tidak menguntungkan. Public relations ini tentu nya di hadapi oleh Docko sendiri selaku pemilik. Membangun citra usaha adalah hal yang ingin Docko capai agar brand dari salon Dreadock dapat berkembang. Salah satu cara yang dilakukan Dreadock adalah dengan melakukan kegiatan seperti event atau mungkin dengan hanya event sponsorship saja. Dengan melakukan hal tersebut, Dreadock sudah dapat terlihat terlibat dalam suatu aktivitas dimana dapat menaikan citranya.

5. Penjualan langsung (direct marketing)

langsung adalah hubungan langsung dengan sasaran konsumen dengan tujuan untuk memperoleh tanggapan segera dan membina hubungan yang abadi dengan konsumen. Direct marketing ini sudah dilakukan sejak berdiri Dreadock melalui media facebook. Dengan minim nya informasi mengenai usaha studio rambut gimbal ini, tentunya direct marketing melalui media sosial sangat diperlukan. Media untuk dapat berkomunikasi langsung dengan Dreadock sekarang adalah instagram, whatsapp dan line. Konsumen atau orang yang tertarik dapat menghubungi nya untuk mendapatkan info langsung mengenai Dreadock.

\section{c. Event marketing}

Menurut Belch (2009) event marketing adalah jenis promosi dimana perusahaan atau merek dikaitkan dengan suatu acara atau kegiatan yang memiliki tema 
dengan tujuan untuk menciptakan pengalaman bagi konsumen dan promosi sebuah produk atau jasa.

Event marketing merupakan komponen penting bagi Dreadock dalam melakukan komunikasi pemasarannya. Ada beberapa kategori event yang dilakukan Dreadock, yang pertama yaitu event yang berkaitan dengan musik. Salah satu Event nya adalah live music yang dinamai dengan nama Kambenoy yang merupakan singkatan dari combine and enjoy. Selain itu kategori event lainnya yang dilakukan oleh Dreadock adalah seperti outing dan DDS Riding. Outing merupakan event yang dilakukan Dreadock dengan travel ke suatu tempat. Lalu salah satu event yang dilakukan oleh Dreadock dengan tujuan untuk menarik konsumen adalah Dreadock Pop Up Studio. Event ini merupakan event yang direncanakan Dreadock untuk datang ke suatu tempat dimana konsumen di tempat tersebut bisa mendapatkan jasa gimbal rambut.

\section{d. Event sponsorship}

Event sponsorship merupakan salah satu strategi komunikasi pemasaran yang dilakukan Dreadock. Hal ini dilakukan Docko dengan tujuan membangun brand dan juga melakukan komunikasi dengan konsumen melalui sebuah event. Menurut Keller (2012) Membangun sebuah event sponsorship membutuhkan strategi dalam pemilihan event, program yang tepat untuk sponsorship, serta mengukur dampak yang akan terjadi terhadap ekuitas merek. Docko mengatakan bahwa partisipasi Dreadock dalam melakukan event dan event sponsorship ini bukan hanya didasarkan pada pemasaran saja. Menurut nya ini salah satu cara yang dilakukan untuk dapat memperlihatkan bahwa Dreadock bukan sekedar cuman ngomongin gimbal aja, namun memperlihatkan gerakannya yang dapat merubah stigma banyak orang.

\section{e. Word of mouth}

Menurut Lovelock and Wright (2007) menyatakan bahwa word of mouth dapat berupa komentar atau rekomendasi yang disebarkan ke pelanggan berdasarkan pengalaman yang diterimanya memiliki pengaruh yang kuat terhadap pengambilan keputusan yang dilakukan oleh pihak lain (Donni Juni Priansa 2017:338). Menurut Docko word of mouth sangat terasa dan terjadi kepada Dreadock. Docko mengatakan bahwa yang penting agar word of mouth ini terjadi adalah brand dan service. Menurutnya service sangat berpengaruh, karena ketika misalnya Dreadock mengalami kesalahan, akan sulit lagi untuk menciptakan image yang baik dan pasti nya akan berpengaruh terhadap word of mouth yang terjadi melalui konsumen.

\section{Simpulan}

Strategi yang digunakan oleh Dreadock Studio dalam menarik minat konsumen menggunakan kegiatan-kegiatan komunikasi pemasran yaitu Bauran promosi, Event, Event sponsorship dan Word of mouth. Dari kempat kegiatan komunikasi pemasaran yang paling berpengaruh untuk menarik minat konsumen adalah Word of mouth dan Event.

Word of mouth merupakan komunikasi yang paling efektif. Sehingga hal paling utama yang dilakukan Dreadock agar word of mouth berjalan dengan baik adalah memaksimalkan dan mengawasi jasa dari padi Studio itu sendiri. Setelah itu 
baru didorong dengan faktor pendukung seperti strategi komunikasi pemasaran yang dilakukan. Pemasaran menggunakan event dan event sponsorship baik untuk mengenalkan dan meningkatkan pengetahuan terhadap Dreadock, memperlihatkan partisipasi Dreadock, dan memperoleh partner dan pelanggan baru.

\section{Ucapan Terima Kasih}

Ucapan terima kasih penulis sampaikan kepada seluruh narasumber yang telah bersedia meluangkan waktu untuk melakukan wawancara dan memberikan informasi kepada penulis selama proses pengumpulan data untuk penelitian ini. Penulis juga berterimakasih kepada seluruh pihak yang telah membantu penelitian ini serta pihak Fakultas Ilmu Komunikasi Universitas Tarumanagara.

\section{Daftar Pustaka}

Belch (2009). Advertising and Promotion. New York: McGraw-Hill.

Gunawan, Imam. (2014). Metode Penelitian Kualitatif: Teori dan Praktik. Jakarta: Bumi Aksara

Kennedy, John E. (2009). Manajemen Event. Jakarta: PT. Bhuana Ilmu Populer.

Kotler, Keller. (2009). Manajemen Pemasaran. Jakarta: Erlangga.

Kotler, Philip dan Armstrong Gary. (2012). Prinsip-Prinsip Pemasaran. Edisi ke dua belas jilid I. Jakarta: Erlangga.

Miles, Matthew B. and A. Michael Huberman. (2007). Qualitative Data Analisis (terjemahan). Jakarta: UI Press.

Moleong, Lexy J. (2009). Metodologi Penelitian Kualitatif. Bandung: PT Remaja Rosdakarya.

Priansa, Donni Juni. (2017). Komunikasi Pemasaran Terpadu Pada Era Media Sosial. Jakarta: CV. Pustaka Setia. 